\title{
Contribuição de material amorfo na gênese de horizontes coesos em Argissolos dos Tabuleiros Costeiros do Ceará ${ }^{1}$
}

\author{
Contribution of amorphous material in the genesis of cohesive horizons of Ultisols in \\ Ceara Coastal Plains
}

\author{
Juliana Matos Vieira ${ }^{2 *}$, Ricardo Espíndola Romero², Tiago Osório Ferreira² e Raimundo Nonato de Assis Júnior²
}

\begin{abstract}
RESUMO - Os Tabuleiros Costeiros, com ocorrência nas regiões Norte, Nordeste e Sudeste do Brasil, apresentam solos com horizontes coesos, os quais podem ocasionar impedimentos físicos à penetração das raízes e à dinâmica da água. No entanto, a gênese desses horizontes ainda é muito questionada. Desta forma, objetivou-se avaliar a influência do material amorfo na coesão desses solos, estudando-se uma topossequência no município de Trairi - CE. Foram descritos e caracterizados (física e quimicamente) três perfis de solos com caráter coeso (P2; P3 e P4) e um perfil (P1) não coeso. Para a avaliação do efeito do material amorfo na coesão dos solos, foram utilizadas amostras dos horizontes Bt1 dos 4 perfis, com e sem extração de material amorfo. Três ciclos de umedecimento e secagem foram aplicados nas amostras e, em seguida, a resistência à penetração (RP) foi determinada. Com base nos resultados, os solos foram enquadrados, taxonomicamente, nas subordens dos Argissolos Amarelos (P1; P2 e P3) e Acinzentados (P4). A maior expressão do caráter coeso foi encontrada em P4, situado na posição mais baixa da paisagem, sugerindo a influência do relevo na intensificação do caráter coeso. Apesar dos baixos teores de argila e de destorroamento, os solos retomaram uma alta RP após apenas três ciclos de umedecimento e secagem. Após a extração de material amorfo, os horizontes coesos dos perfis P2 e P4 apresentaram uma significativa redução da resistência à penetração, indicando que estes compostos atuam na gênese de horizontes coesos.
\end{abstract}

Palavras-chave: Caráter coeso. Compostos amorfos. Pedogênese.

\begin{abstract}
The coastal plains, in the North, Northeast and Southeast Brazil, soils with cohesive layer are common, and can cause physical impediment to root and water. However, the genesis of these horizons is still unknown. The main objective of this work was to evaluate the influence of amorphous materials on the cohesion processes with cohesive layers from a toposequence in Trairi - CE. Four soil profiles were described and characterized (physically and chemically). Three soils present cohesive layers (P2, P3 and P4) and one (P1) did not. To evaluate the effect of amorphous material in the cohesion, samples of Bt1 horizons were subjected to two treatments: with and without extraction of amorphous material. Samples (with and without extraction) were subjected to three cycles of wetting and drying and then the penetration resistance (PR) was determined. Based on the chemical and physical analysis, the soils were classified as Ultisols. The highest expression of the cohesive character was found in $\mathrm{P} 4$, located in the lowest position of the landscape, suggesting the influence of relief on the intensification of the cohesion. Despite the low clay content and the loosening of the soil, a high PR was achieved after only a few cycles of wetting and drying. After extraction of amorphous material, the cohesive horizons of profiles P2 and P4 showed a significant reduction of PR, indicating that these compounds act in the genesis of cohesive layers.
\end{abstract}

Key words: Hardsetting soils. Amorphous compounds. Pedogenesis.

\footnotetext{
*Autor para correspondência

${ }^{1}$ Recebido para publicação em 15/03/2011; aprovado em 11/03/2012

Parte da Monografia da primeira autora, apresentada ao Departamento de Ciências do Solo da Universidade Federal do Ceará -UFC

${ }^{2}$ Departamento de Ciências do Solo, Centro de Ciências Agrárias, Universidade Federal do Ceará/UFC, Fortaleza-CE, Brasil, juliana.vieira07@ yahoo.com.br, reromero@ufc.br, tiago@ufc.br, assisjr@ufc.br
} 


\section{INTRODUÇÃO}

Os solos dos Tabuleiros Costeiros encontram-se distribuídos por quase toda faixa costeira do Brasil, normalmente são profundos e ocorrem associados a relevo plano a suave ondulado, favorecendo a exploração agrícola e, segundo Souza et al. (2004) e Cintra et al. (2009), são de grande importância no Nordeste para a produção de citros (Citrus sinensis L), coco (Cocus nucifera), mandioca (Manihot esculenta), caju (Anacardium occidentale), cacau (Theobroma cacao), mamão (Carica papaya), abacaxi (Ananas Sativus), dendê (Elaeis guianeensis) e cana-deaçúcar (Saccharum officinarum L), sendo, ainda utilizadas para pastagem (COSTA et al., 2009) e cultivo de eucalipto (Eucalyptus globulus Labill) (MOREAU et al., 2006a).

Entretanto, a presença de horizontes coesos nesses solos atua como um contraponto às suas potencialidades agrícolas, pois acarreta sérias restrições ao aprofundamento do sistema radicular (CINTRA; PORTELA; NOGUEIRA, 2004). Os horizontes coesos são definidos pelo Sistema Brasileiro de Classificação de Solos - SiBCS (EMPRESA BRASILEIRA DE PESQUISAAGROPECUÁRIA, 2006) como horizontes pedogenéticos subsuperficiais adensados, muito resistentes à penetração da faca com consistência seca muito dura a extremamente dura, passando a friável ou firme quando úmido.

A identificação de solos com caráter coeso tem sido feita de forma qualitativa, em campo, através da descrição morfológica de perfis. Entretanto, pode-se destacar a utilização da resistência à penetração como um atributo quantitativo para essa identificação (GIAROLA et al., 2003), tendo em vista que, aliada a outros parâmetros (densidade do solo e porosidade), esta medida pode ser útil na caracterização do comportamento coeso. A gênese dos horizontes coesos permanece cercada de dúvidas, entretanto, sabe-se que sua natureza é pedogenética (LIMA NETO et al., 2010), podendo estar associada a diferentes processos, tais como: argiluviação; presença de argila dispersa nos microporos e adensamento pela alternância de ciclos de umedecimento e secagem (CINTRA; LIBARDI; SILVA, 1997).

Estudos também indicam que a gênese dos horizontes coesos pode estar relacionada à cimentação fraca e temporária promovida por compostos amorfos envolvendo material sílicoaluminoso (ARAÚJO FILHO; CARVALHO; SILVA, 2001) que, no período seco passaria por processo de polimerização e precipitação e, no período úmido, a despolimerização contribuiria para a condição de friabilidade do solo.

Deve-se destacar ainda que, em solos da Austrália, estudos (CHARTRES; KIRBY; AUPACH, 1990; FRANZMEIER; CHARTES;WOOD, 1996) também destacam a sílica amorfa como o principal agente cimentante em solos com atributo hardsetting, correlato ao caráter coeso (GIAROLA; SILVA, 2002).
Por outro lado, Moreau et al. (2006b), em trabalho mais recente, não constatou a ação de agentes cimentantes nos horizontes coesos no estado da Bahia, indicando que a formação destes horizontes não estaria relacionada à presença de componentes amorfos.

Com base no exposto, fica clara a existência de estudos inconclusivos com relação à efetiva participação de material amorfo na gênese de horizontes coesos. Dessa forma, objetivou-se com este trabalho avaliar a influência destes compostos na pedogênese de solos com caráter coeso, em uma topossequência dos Tabuleiros Costeiros do Ceará.

\section{MATERIAL E MÉTODOS}

\section{Área de estudo}

O estudo foi realizado no Município de Trairi, localizado no centro-norte do estado do Ceará (Figura $1 \mathrm{~A})$, entre as coordenadas $03^{\circ} 10^{\prime}$ e $03^{\circ} 35^{\prime} \mathrm{S}$ e $39^{\circ} 31^{\prime}$ e $39^{\circ} 09^{\prime}$ W. Segundo a classificação de Köppen, o clima é do tipo Aw, tropical quente com chuvas de verão. A temperatura média anual é superior a $24{ }^{\circ} \mathrm{C}$ e a média pluviométrica é de $1.589 \mathrm{~mm}$ ano $^{-1}$ (INSTITUTO DE PESQUISA E ESTRATÉGIA ECONÔMICA DO CEARÁ, 2005).

\section{Coleta de solos}

Para o estudo foram coletados e analisados quatro perfis de solos (P1, P2, P3 e P4) de uma topossequência (Figura 1B) em área de exploração agrícola. Os perfis P1 e P4 localizam-se em áreas cultivadas com caju (Anacardium occidentale), enquanto os perfis P2 e P3 em áreas cultivadas com noni (Morinda citrifolia) e com coco (Cocus nucifera), respectivamente. Para coleta de amostras e descrição morfológica foi utilizada a metodologia proposta por Santos et al. (2005).

Posteriormente, para a realização das determinações químicas e físicas para fins de classificação, as amostras foram secas ao ar, destorroadas e tamisadas em peneira com malha de $2 \mathrm{~mm}$.

\section{Análises químicas}

As análises químicas para fins de caracterização e classificação foram realizadas segundo Empresa Basileira de Pesquisa Agropecuária (1997). Foram determinados: pH em água e em solução de cloreto de potássio $(\mathrm{KCl})$ $1 \mathrm{~mol} \mathrm{~L}^{-1}$, empregando-se relação solo:solução de 1:2,5; acidez potencial por extração com solução de acetato de cálcio $0,5 \mathrm{~mol} \mathrm{~L}^{-1}$ a pH 7,0; complexo sortivo; P extraível com Mehlich-1 (por colorimetria); carbono orgânico total (CO) através da oxidação via úmida com dicromato de potássio em meio sulfúrico. Também foram calculados soma de bases (SB), capacidade de troca de cátions (T), 
Figura 1 - Localização do município de Trairi-CE (UTM Norte: 9.637.700 e Oeste: 470.300) onde está situada a área de estudo (A) e modelo de elevação digital da área (B) com a localização dos perfis analisados e o fluxo preferencial de água
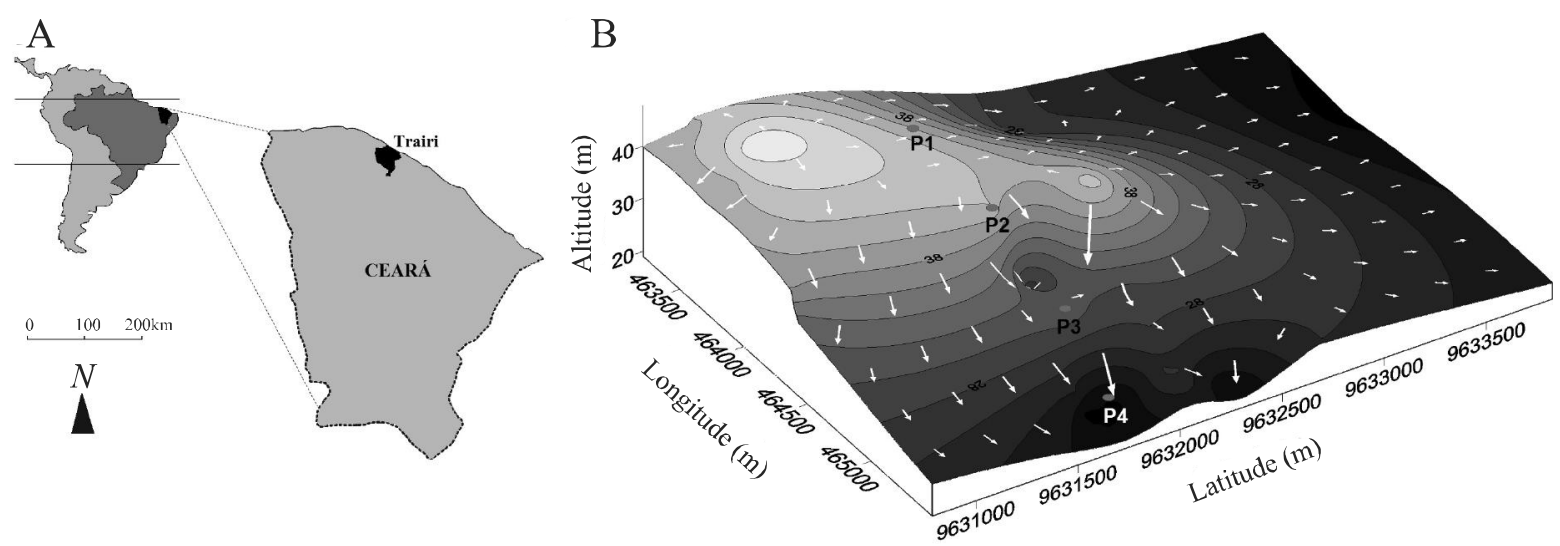

percentagem de saturação por bases $(\mathrm{V} \%)$ e percentagem de saturação por sódio (PST).

\section{Análises físicas}

A análise granulométrica (EMPRESA BRASILEIRA DE PESQUISA AGROPECUÁRIA, 1997) foi realizada pelo método da pipeta, utilizando-se como dispersante químico o hexametafosfato de sódio e agitação rápida (10 minutos). A densidade do solo foi determinada (EMPRESA BRASILEIRA DE PESQUISA AGROPECUÁRIA, 1997) nos horizontes Bt1 dos quatro perfis, utilizando-se cinco repetições para cada horizonte.

Para a avaliação da resistência do solo à penetração, utilizaram-se amostras de TFSA dos horizontes Bt1 dos 4 perfis de solo. As amostras foram divididas em dois conjuntos de subamostras. Em um dos conjuntos foi realizada a extração de material amorfo com solução de oxalato de amônio (EMPRESA BRASILEIRA DE PESQUISA AGROPECUÁRIA, 1997). As amostras submetidas ao processo de extração foram centrifugadas, o sobrenadante foi descartado e os solos contidos nos tubos da centrífuga foram lavados com água destilada, colocados em béqueres e secos em estufa a $50{ }^{\circ} \mathrm{C}$.

Os materiais dos dois tratamentos (com extração e sem extração de amorfos), com quatro repetições, foram colocados em tubos de PVC de $5 \mathrm{~cm}$ de altura e $2 \mathrm{~cm}$ de diâmetro, previamente forrados com pano na extremidade inferior. Posteriormente, os tubos foram colocados em uma bandeja e as amostras submetidas a três ciclos de umedecimento e secagem. No umedecimento foi adicionada água destilada na base da bandeja, para saturar a amostra via ascensão capilar. Após o umedecimento (até a porção superficial), o excesso de água da bandeja foi descartado e o material foi seco ao ar por cinco dias para a retomada de um novo ciclo de umedecimento.
Depois do último ciclo $\left(3^{\circ}\right)$, as amostras foram secas ao ar durante cinco dias em casa de vegetação e a resistência do solo à penetração foi medida nas duas parcelas, usando-se um penetrômetro eletrônico da marca Marconi (MA 933), acoplado a um computador, com velocidade constante de $1 \mathrm{~cm} \mathrm{~min}^{-1}$.

\section{Análises estatísticas}

Os dados de densidade e resistência à penetração foram submetidos à análise de variância e a comparação das médias foi realizada pelo teste de Tukey $(\alpha=0,05)$, utilizando-se o software SISVAR (versão 5.3).

\section{RESULTADOS E DISCUSSÃO}

\section{Caracterização morfológica}

Os perfis estudados apresentam a mesma sequência de horizontes: A - E - B (Tabela 1), sendo todos profundos, com espessuras superiores a $167 \mathrm{~cm}$. Os solos apresentaram cores de matizes predominantemente amarelos, 10YR e 7,5YR, com valores variando de 3 a 5 e cromas de 2 a 8 , à exceção do perfil $\mathrm{P} 4$, de cor predominantemente acinzentada (matiz 10YR, valores $\geq 5$ e cromas $<4$ ), indicativo de má drenagem.

Estas cores amareladas (associadas à goethita) e acinzentadas estão relacionadas aos baixos teores de óxidos de ferro no material de origem (MELO et al., 2002a, 2002b) e ao processo de desferrificação, em função das condições pedoclimáticas (CORRÊA et al., 2008; LIMA NETO et al., 2010; MOREAU et al., 2006a).

A consistência extremamente dura quando seca, e friável a muito friável quando úmido, nos horizontes Bt1 dos perfis P2, P3 e P4, evidenciou, segundo os critérios 
estabelecidos no SiBCS (EMPRESA BRASILEIRA DE PESQUISA AGROPECUÁRIA, 2006), a presença de horizontes coesos nestes solos (Tabela 1). Esta ocorrência em grandes profundidades $(>90 \mathrm{~cm})$ também foi encontrada por Lima et al. (2005), associada a solos com B textural.

Os horizontes Bt coesos dos perfis analisados apresentaram estrutura maciça com tendência à formação de blocos subangulares. Resultados semelhantes foram encontrados por Lima et al. (2004) em solos com horizontes coesos nos Tabuleiros Costeiros do Ceará (Pacajus e Camocim). Estudos micromorfológicos (GIAROLA et al., 2003; LIMA et al., 2006) mostram que este tipo de estrutura, nos horizontes coesos, apresenta-se com uma menor porosidade e um plasma caulinítico mais denso que recobre os grãos de quartzo.

Tabela 1 - Características morfológicas dos quatro perfis estudados

\begin{tabular}{|c|c|c|c|c|c|c|}
\hline \multirow{2}{*}{ Horizonte } & \multirow{2}{*}{$\frac{\text { Profundidade }}{(\mathrm{cm})}$} & \multicolumn{2}{|c|}{ Cor (Munsell) } & \multirow[t]{2}{*}{ Estrutura $^{(1)}$} & \multicolumn{2}{|c|}{ Consistência $^{(2)}$} \\
\hline & & Seca & Úmida & & Seca & Úmida \\
\hline \multicolumn{7}{|c|}{ Perfil-1 Argissolo Amarelo Eutrófico solódico } \\
\hline Ap1 & $0-10$ & $10 Y R 5 / 3$ & $10 \mathrm{YR} 3 / 2$ & $1 \mathrm{PM} B S$ & LD & $\mathrm{MFr}$ \\
\hline Ap2 & $10-21$ & 10YR 5/6 & $10 Y R 4 / 3$ & $1 \mathrm{PM} B \mathrm{~S}$ & LD & MFr \\
\hline $\mathrm{AE}$ & $21-42$ & 10YR 5/4 & 10YR 4/4 & $1 \mathrm{PM} B \mathrm{~S}$ & LD & $\mathrm{MFr}$ \\
\hline $\mathrm{E}$ & $42-72$ & 10YR 6/4 & 10YR 5/4 & $1 \mathrm{PM} B S$ & LD & MFr \\
\hline $\mathrm{EB}$ & $72-90$ & 10YR 6/6 & 10YR 5/6 & $12 \mathrm{M} \mathrm{G} \mathrm{BS}$ & LD & MFr \\
\hline Bt1 & $90-138$ & 10YR 7/6 & 10YR 5/6 & $12 \mathrm{M} \mathrm{BS}$ & LD & MFr \\
\hline $\mathrm{Bt} 2$ & $138-167^{+}$ & 10YR 7/6 & 10YR 6/6 & $2 \mathrm{M} \mathrm{G} \mathrm{BS}$ & LD & MFr \\
\hline \multicolumn{7}{|c|}{ Perfil-2 Argissolo Amarelo Distrocoeso arênico } \\
\hline Ap & $0-16$ & $7,5 \mathrm{YR} 5 / 3$ & 7,5YR 3/4 & $1 \mathrm{M} \mathrm{BS}$ & $\mathrm{Ma} / \mathrm{LD}$ & $\mathrm{MFr}$ \\
\hline $\mathrm{E}$ & $16-54$ & 7,5YR 6/4 & 7,5YR 5/4 & $12 \mathrm{M} \mathrm{BS}$ & $\mathrm{Ma} / \mathrm{LD}$ & MFr \\
\hline $\mathrm{EB}$ & $54-92$ & 10YR 6/6 & $10 Y R 5 / 8$ & $2 \mathrm{M} \mathrm{G} \mathrm{BS}$ & $\mathrm{LD}$ & MFr \\
\hline Bt1 & $92-125$ & 10YR 6/6 & 10YR 5/8 & $\mathrm{Mc} / \mathrm{BS}$ & ED & Fr \\
\hline $\mathrm{Bt} 2$ & $125-155$ & 10YR 6/8 & 10YR 5/8 & $2 \mathrm{M} \mathrm{G} \mathrm{BS}$ & $\mathrm{LD} / \mathrm{D}$ & MFr \\
\hline Bt3 & $155-176$ & 10YR 6/8 & 7,5YR 5/8 & $2 \mathrm{M} \mathrm{G} \mathrm{BS}$ & LD & MFr \\
\hline Bt4 & $176-197^{+}$ & 10YR 6/8 & 7,5YR 5/8 & $2 \mathrm{M} \mathrm{G} \mathrm{BS}$ & $\mathrm{LD}$ & MFr \\
\hline \multicolumn{7}{|c|}{ Perfil-3 Argissolo Amarelo Distrocoeso típico } \\
\hline Ap & $0-17$ & 10YR 5/3 & $10 Y R 3 / 3$ & 12 P M BS & $\mathrm{Ma} / \mathrm{LD}$ & Solto \\
\hline $\mathrm{E}$ & $17-47$ & 10YR 6/4 & 10YR 5/6 & $2 \mathrm{P} M \mathrm{BS}$ & LD & MFr \\
\hline EB & $47-71$ & 10YR 6/4 & 10YR 5/8 & $2 \mathrm{P}$ M BS & LD & MFr \\
\hline $\mathrm{BE}$ & $71-91$ & 10YR 7/6 & 10YR 5/6 & $2 \mathrm{M} \mathrm{G} \mathrm{BS}$ & $\mathrm{LD} / \mathrm{D}$ & MFr \\
\hline Bt1 & $91-142$ & 7,5YR 6/8 & 7,5YR 5/8 & $\mathrm{Mc} / \mathrm{BS}$ & $\mathrm{ED}$ & Fri/MFr \\
\hline $\mathrm{Bt} 2$ & $142-170^{+}$ & 7,5YR 7/8 & 7,5YR 5/8 & $\mathrm{Mc} / \mathrm{BS}$ & ED & $\mathrm{MFr}$ \\
\hline \multicolumn{7}{|c|}{ Perfil-4 Argissolo Acinzentado Eutrófico abrúptico } \\
\hline Ap & $0-13$ & 10YR 6/1 & $10 \mathrm{YR} 3 / 2$ & $1 \mathrm{P} \mathrm{M} \mathrm{BS}$ & Ma & MFr \\
\hline A & $13-53$ & $10 \mathrm{YR} 6 / 2$ & $10 \mathrm{YR} 4 / 2$ & $1 \mathrm{M} \mathrm{BS}$ & LD & MFr \\
\hline E1 & $53-87$ & 10YR 6/2 & $10 Y R 5 / 3$ & $1 \mathrm{PM} B \mathrm{~S}$ & $\mathrm{Ma}$ & $\mathrm{MFr}$ \\
\hline E2 & $87-105$ & 10YR 5/2 & $10 Y R 5 / 3$ & 12 P M BS & $\mathrm{Ma} / \mathrm{LD}$ & $\mathrm{MFr}$ \\
\hline EB & $105-142$ & $10 \mathrm{YR} 6 / 2$ & $10 \mathrm{YR} 5 / 3$ & $2 \mathrm{M} \mathrm{Bs}$ & LD & MFr \\
\hline Bt1 & $142-170^{+}$ & 10YR 6/2 & 10YR 5/2 & $\mathrm{Mc} / \mathrm{BS}$ & ED & $\mathrm{Fr}$ \\
\hline
\end{tabular}

${ }^{(1)}$ Estrutura: 1: fraca; 2: moderada; P: pequena; M: média; G: grande; BS: blocos subangulares; Mc: maciça; ${ }^{\left({ }^{2}\right)}$ Consistência: Ma: macia; LD: ligeiramente dura; D: dura; ED: extremamente dura; MFr: muito friável; Fr: friável 


\section{Caracterização química}

Os resultados das determinações químicas mostram que os solos estudados apresentam limitada disponibilidade de nutrientes devido aos baixos valores de capacidade de troca de cátions (CTC) e soma de bases (SB) encontrados (Tabela 2). Estudos prévios (MOREAU et al., 2006a) constataram a prevalência de solos dos Tabuleiros Costeiros quimicamente pobres, fundamentalmente, em função da sua gênese estar associada a materiais previamente alterados e com avançado estado de intemperismo. Apesar da ocorrência de eutrofismo ( $\mathrm{V} \geq 50 \%$ ) nos perfis P1 e P4 (Tabela 2), devido à baix a CTC que estes solos apresentam, os valores de $\mathrm{V}$ elevados estão associados a baixos teores absolutos de SB, refletindo sua pobreza em nutrientes.

No caso específico do perfil $\mathrm{P} 4$, cabe ressaltar a inadequação de sua classificação no $3^{\circ}$ nível categórico

Tabela 2 - Características químicas dos quatro perfis estudados

\begin{tabular}{|c|c|c|c|c|c|c|c|c|c|c|c|c|c|c|}
\hline \multirow[t]{2}{*}{ Hor } & \multirow{2}{*}{$\frac{\text { Prof. }}{\mathrm{cm}}$} & \multirow{2}{*}{$\frac{\mathrm{CO}^{(1)}}{\mathrm{g} \mathrm{kg}^{-1}}$} & \multicolumn{2}{|c|}{$\mathrm{pH}$} & $\mathrm{Ca}^{2+}$ & $\mathrm{Mg}^{2+}$ & $\mathrm{K}^{+}$ & $\mathrm{Na}^{+}$ & $\mathrm{Al}^{3+}$ & $\mathrm{H}+\mathrm{Al}$ & $\mathrm{SB}^{(2)}$ & $\mathrm{T}^{(3)}$ & $\mathrm{V}^{(4)}$ & $\operatorname{PST}^{(5)}$ \\
\hline & & & $\mathrm{H}_{2} \mathrm{O}$ & $\mathrm{KCl}$ & \multicolumn{8}{|c|}{ 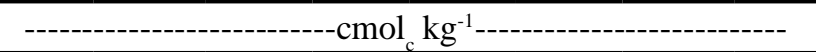 } & \multicolumn{2}{|c|}{------\%------ } \\
\hline \multicolumn{15}{|c|}{ Perfil-1 Argissolo Amarelo Eutrófico solódico } \\
\hline Ap1 & $0-10$ & 8,3 & 6,2 & 4,8 & 1,60 & 1,00 & 0,07 & 0,04 & 0,20 & 1,40 & 2,7 & 4,1 & 66 & 1,1 \\
\hline Ap2 & $10-21$ & 4,0 & 5,8 & 4,3 & 0,80 & 0,80 & 0,06 & 0,07 & 0,20 & 1,00 & 1,7 & 2,7 & 63 & 2,6 \\
\hline $\mathrm{AE}$ & $21-42$ & 3,4 & 5,9 & 4,7 & 0,80 & 0,60 & 0,04 & 0,12 & 0,20 & 0,70 & 1,6 & 2,2 & 71 & 5,5 \\
\hline $\mathrm{E}$ & $42-72$ & 1,9 & 6,1 & 4,7 & 0,80 & 0,60 & 0,05 & 0,14 & 0,40 & 0,90 & 1,6 & 2,5 & 64 & 5,6 \\
\hline EB & $72-90$ & 3,2 & 5,7 & 4,5 & 0,80 & 0,60 & 0,06 & 0,17 & 0,40 & 0,60 & 1,6 & 2,2 & 73 & 7,7 \\
\hline Bt1 & $90-138$ & 4,1 & 5,6 & 4,2 & 0,80 & 0,20 & 0,08 & 0,18 & 0,60 & 0,90 & 1,3 & 2,2 & 58 & 8,2 \\
\hline $\mathrm{Bt} 2$ & $138-167^{+}$ & 3,1 & 5,4 & 4,3 & 0,80 & 0,80 & 0,08 & 0,17 & 0,20 & 0,80 & 1,9 & 2,7 & 70 & 6,3 \\
\hline \multicolumn{15}{|c|}{ Perfil-2 Argissolo Amarelo Distrocoeso arênico } \\
\hline Ap & $0-16$ & 3,7 & 6,1 & 5,0 & 1,20 & 0,80 & 0,05 & 0,02 & 0,30 & 1,50 & 2,1 & 3,6 & 58 & 0,6 \\
\hline $\mathrm{E}$ & $16-54$ & 1,8 & 5,7 & 4,4 & 0,80 & 0,00 & 0,01 & 0,00 & 0,20 & 0,70 & 0,8 & 1,9 & 42 & 0,0 \\
\hline EB & $54-92$ & 2,1 & 5,7 & 4,3 & 0,80 & 0,00 & 0,05 & 0,05 & 0,10 & 1,20 & 0,9 & 2,1 & 43 & 2,4 \\
\hline Bt1 & $92-125$ & 1,8 & 5,9 & 4,4 & 0,60 & 0,40 & 0,07 & 0,01 & 0,20 & 1,20 & 1,1 & 2,3 & 47 & 0,4 \\
\hline $\mathrm{Bt} 2$ & $125-155$ & 1,9 & 5,9 & 4,5 & 0,80 & 0,20 & 0,09 & 0,05 & 0,30 & 1,40 & 1,1 & 2,5 & 45 & 2,0 \\
\hline $\mathrm{Bt} 3$ & $155-176$ & 1,8 & 5,9 & 4,7 & 1,00 & 0,40 & 0,09 & 0,07 & 0,30 & 1,70 & 1,6 & 3,3 & 48 & 2,1 \\
\hline $\mathrm{Bt} 4$ & $176-197^{+}$ & 1,5 & 5,8 & 5,0 & 1,00 & 0,20 & 0,08 & 0,05 & 0,30 & 1,30 & 1,3 & 2,6 & 51 & 1,9 \\
\hline \multicolumn{15}{|c|}{ Perfil-3 Argissolo Amarelo Distrocoeso típico } \\
\hline Ap & $0-17$ & 5,0 & 6,0 & 4,8 & 1,40 & 1,60 & 0,11 & 0,04 & 0,10 & 1,70 & 3,2 & 4,9 & 65 & 0,8 \\
\hline $\mathrm{E}$ & $17-47$ & 2,0 & 6,5 & 5,2 & 0,80 & 1,20 & 0,13 & 0,03 & 0,20 & 1,20 & 2,2 & 3,4 & 64 & 0,9 \\
\hline EB & $47-71$ & 1,8 & 5,8 & 4,7 & 0,60 & 0,80 & 0,09 & 0,05 & 0,20 & 1,60 & 1,5 & 3,1 & 49 & 1,6 \\
\hline $\mathrm{BE}$ & $71-91$ & 2,1 & 5,5 & 4,3 & 0,60 & 0,40 & 0,25 & 0,04 & 0,30 & 1,80 & 1,3 & 3,1 & 42 & 1,3 \\
\hline Bt1 & $91-142$ & 2,1 & 4,8 & 4,1 & 0,80 & 1,20 & 0,15 & 0,05 & 0,80 & 2,40 & 2,2 & 4,6 & 48 & 1,1 \\
\hline $\mathrm{Bt} 2$ & $142-170^{+}$ & 1,9 & 5,0 & 4,1 & 1,20 & 0,80 & 0,12 & 0,04 & 0,70 & 2,10 & 2,2 & 4,3 & 51 & 0,9 \\
\hline \multicolumn{15}{|c|}{ Perfil-4 Argissolo Acinzentado Eutrófico abrúptico } \\
\hline Ap1 & $0-13$ & 17,4 & 5,7 & 4,5 & 1,60 & 1,40 & 0,11 & 0,13 & 0,40 & 2,20 & 3,2 & 5,4 & 60 & 2,4 \\
\hline Ap2 & $13-53$ & 5,8 & 6,3 & 5,1 & 0,80 & 1,00 & 0,04 & 0,18 & 0,20 & 0,85 & 2,0 & 2,9 & 70 & 6,2 \\
\hline $\mathrm{E}$ & $53-87$ & 4,3 & 6,4 & 4,9 & 1,00 & 0,80 & 0,04 & 0,16 & 0,20 & 0,75 & 2,0 & 2,8 & 73 & 5,7 \\
\hline $\mathrm{EB}$ & $87-105$ & 3,3 & 5,9 & 4,7 & 0,80 & 0,40 & 0,04 & 0,19 & 0,60 & 0,90 & 1,4 & 2,3 & 61 & 8,3 \\
\hline $\mathrm{BE}$ & $105-142$ & 3,3 & 5,5 & 4,5 & 0,80 & 0,00 & 0,06 & 0,16 & 0,40 & 0,90 & 1,0 & 1,9 & 53 & 8,4 \\
\hline Bt1 & $142-170^{+}$ & 4,0 & 5,3 & 4,2 & 0,80 & 0,60 & 0,09 & 0,22 & 0,60 & 1,45 & 1,7 & 3,2 & 54 & 6,9 \\
\hline
\end{tabular}

(1) - CO: Carbono orgânico; ${ }^{(2)}$ - SB: Soma de bases; ${ }^{(3)}$ - T: Capacidade de Troca de Cátions ${ }^{(4)}$ - V: Saturação por bases; ${ }^{(5)}$ - PST: Porcentagem de sódio trocável 
como Argissolo Acinzentado Eutrófico uma vez que este perfil, associado ao eutrofismo, apresenta o caráter coeso. Neste sentido, sugere-se que o caráter coeso conste no $3^{\circ}$ nível categórico na subordem dos Argissolos Acinzentados, uma vez que sua presença pode limitar o desenvolvimento do sistema radicular e a dinâmica de água no solo (CINTRA et al., 2004), criando-se o grande grupo “Argissolos Acinzentados Eutrocoesos". Esta opção de enquadramento já é adotada na subordem dos Argissolos Amarelos e está de acordo com as bases e critérios estabelecidos para caracterizar o $3^{\circ}$ nível categórico (presença de horizontes ou propriedades que restringem o desenvolvimento das raízes e afetam o movimento da água no solo) (EMPRESA BRASILEIRA DE PESQUISA AGROPECUÁRIA, 2006).

Observa-se uma tendência de acúmulo de $\mathrm{Na}^{+}$em profundidade, semelhante ao descrito por Aquino et al. (2008) em área irrigada dos Tabuleiros Costeiros do Ceará. Este comportamento proporcionou alta saturação por sódio

Tabela 3 - Análise granulométrica dos quatro perfis estudados

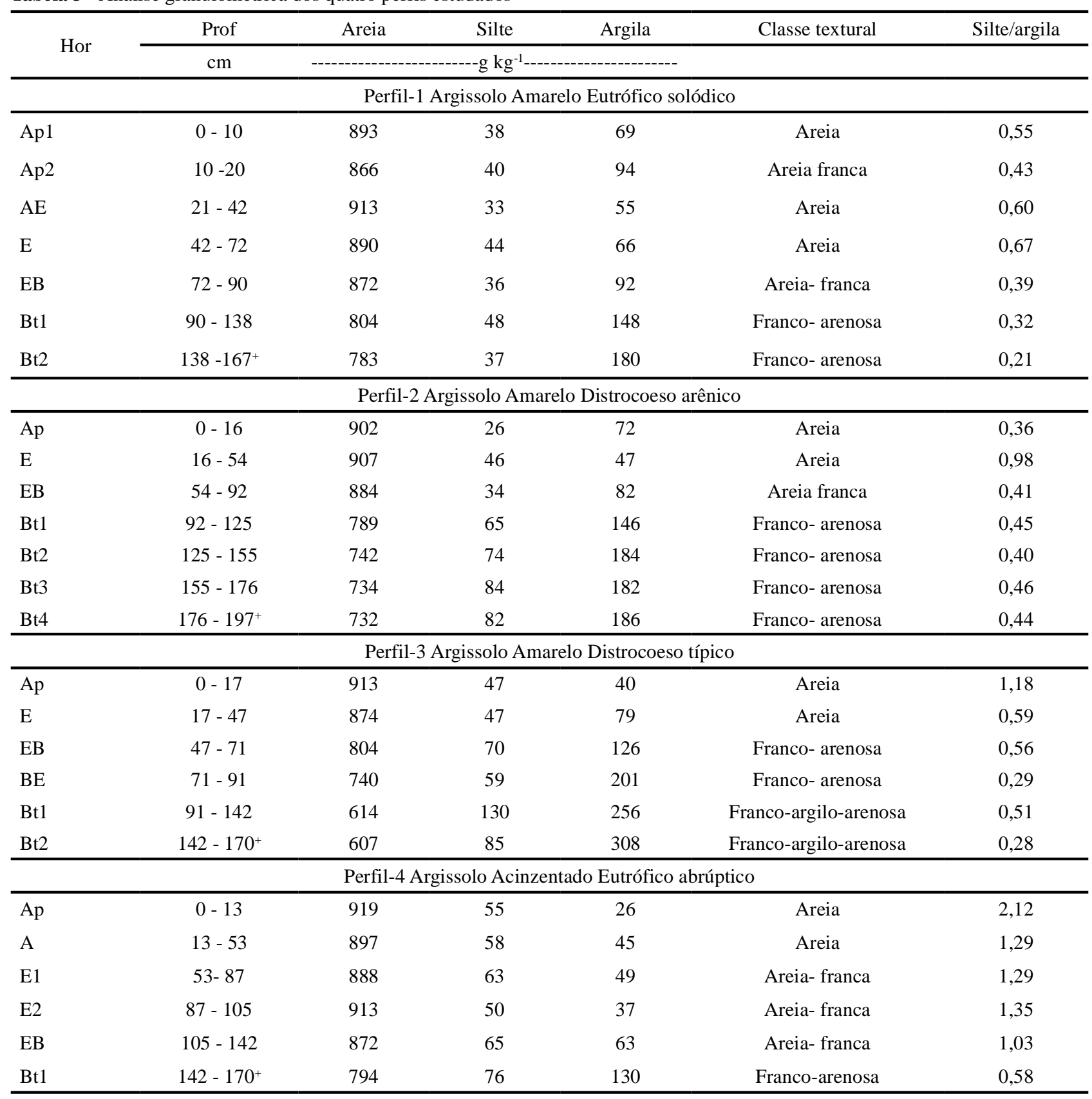


(PST) nos perfis P1 $(8,2 \%)$ e P4 (8,4\%) (Tabela 2$)$ e, assim, o caráter solódico nesses solos.

\section{Caracterização física}

A análise granulométrica mostra o predomínio da fração areia em todos os solos, especialmente nos horizontes superficiais. Resultado semelhante aos encontrados por Lima et al. (2004); Aquino et al. (2008) para outros solos dos Tabuleiros Costeiros do Ceará. Embora ocorra um incremento de argila em profundidade (Tabela 3), a predominância de areia associada aos horizontes coesos contribui para a baixa capacidade de armazenamento de água nesses perfis, aumentando a vulnerabilidade das culturas aos déficits hídricos, comuns nos Tabuleiros Costeiros (CINTRA et al., 2009).

A textura dos horizontes estudados variou de francoargilo-arenosa no perfil P3 (Bt1 e Bt2) a franco-arenosa nos perfis P2 e P4 (Bt1), (Tabela 3). No caso do perfil P3, a textura encontrada está de acordo com o observado por outros autores em solos com a presença de horizontes coesos (LIMA NETO et al., 2009; MAIA, 2004; SANTANA et al., 2006). Já os horizontes Bt1 dos perfis P2 e P4 caracterizamse por conteúdos de argila inferiores àqueles citados por estes autores, mas, dentro dos limites estabelecidos na descrição do caráter coeso pelo SiBCS (EMPRESA BRASILEIRA DE PESQUISA AGROPECUÁRIA, 2006) e superiores aos encontrados por Cintra et al. (2009).

Todos os perfis estudados apresentaram baixos teores de silte (26 a $130 \mathrm{~g} \mathrm{~kg}^{-1}$; Tabela 3), o que também refletiu em baixos valores de relação silte/argila. Estudos prévios, realizados em Argissolos de Tabuleiros Costeiros com presença de caráter coeso (LIMA NETO et al., 2009; MOREAU et al., 2006a) consideram que os baixos valores desta relação estão associados ao pré-intemperismo a que foram submetidos os sedimentos da Formação Barreiras.

Os maiores valores darelação silte/argila observados em P4 (Tabela 3), são conotativos de um menor grau de intemperismo e podem estar associados à posição do solo na paisagem. Por estar localizado na porção mais baixa e côncava (Figura 1B) e, portanto, sujeito ao acúmulo de soluções via fluxos hídricos de superfície e subsuperfície (VIDAL-TORRADO; LEPCH; CASTRO, 2005), o intemperismo hidrolítico (perda de sílica e bases), comum em solos sem problemas de drenagem, não seria tão intenso neste perfil. Esta afirmação é corroborada pela maior atividade de argila do horizonte Bt1 deste perfil (24,6 cmol $\mathrm{kg}^{-1}$ de argila), comparada a dos perfis P1, P2 e P3 $\left(14,8 ; 15,7\right.$ e $8,59 \mathrm{cmol}_{\mathrm{c}} \mathrm{kg}^{-1}$ de argila, respectivamente).

Os valores de densidade do solo (Ds) nos horizontes coesos variaram de $1,66 \mathrm{Mg} \mathrm{cm}^{-3} \mathrm{em} \mathrm{P} 2$ a $1,73 \mathrm{Mg} \mathrm{cm}^{-3} \mathrm{em}$ P4 (Figura 2), estando de acordo com valores encontrados por outros autores (LIMA et al., 2005; SANTANA et al., 2006) que estudaram solos coesos desenvolvidos de sedimentos da
Formação Barreiras. Já o horizonte Bt1 do perfil P1 apresentou valor de densidade de $1,53 \mathrm{Mg} \mathrm{cm}^{-3}$, evidenciando a ausência do caráter coeso neste horizonte. Estes resultados estão de acordo com a identificação do caráter coeso feito através da descrição morfológica no campo (Tabela 1), indicando que a morfologia consiste em ferramenta eficiente na identificação destes horizontes, especialmente se associado à determinação da Ds (LIMA NETO et al., 2009).

A alta Ds do horizonte coeso pode ser resultante do arranjamento cerrado das partículas, visto que,

Figura 2 - Valores médios de densidade dos horizontes Bt1 dos quatro perfis estudados

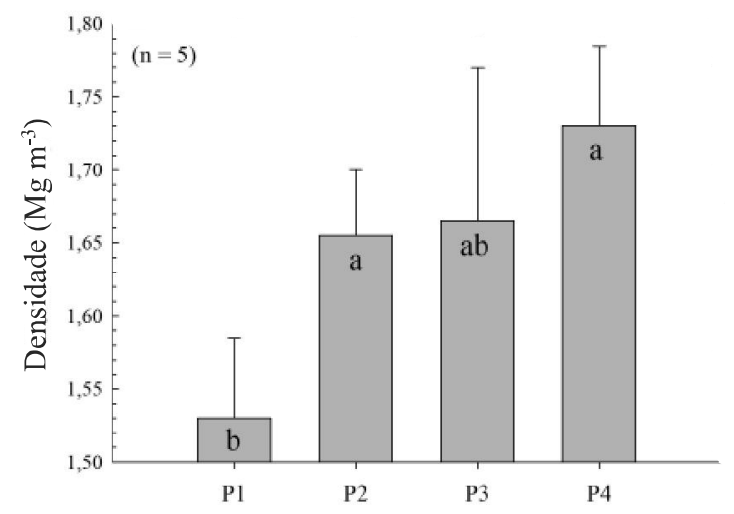

Médias seguidas pelas mesmas letras não diferem estatisticamente pelo teste de Tukey $(\alpha=0,05)$

horizontes de composição similar, porém sem este tipo de arranjamento dos componentes e com maior número de macroporos, possuem valores mais baixos de densidade do solo. A mineralogia predominantemente caulinítica desses solos (LIMA et al., 2005) pode favorecer o adensamento, no entanto, estudos indicam (GIAROLA et al., 2009) que o grau de ordenamento da caulinita em áreas dos Tabuleiros Costeiros não permite associar o empacotamento da caulinita com a ocorrência do caráter coeso nestes solos.

O maior valor de densidade encontrado no horizonte coeso do Argissolo Acinzentado (P4; 1,73 g.cm ${ }^{-3}$ ) está de acordo com o relatado por Lima et al. (2005) e Lima Neto et al. (2009). Em ambos os trabalhos os autores, estudando o comportamento físico de solos com caráter coeso da região Nordeste, evidenciaram maiores valores de Ds em Argissolos Acinzentados. Neste sentido, o horizonte coeso do perfil P4 (Bt1) apresentou Ds $\left(1,73 \mathrm{Mg} \mathrm{cm}^{-3}\right)$ inferior àquela observada em horizonte coeso descrito por Lima et al. (2005) no Ceará $\left(1,75 \mathrm{Mg} \mathrm{cm}^{-3}\right)$ e superior à encontrada por Lima Neto et al. (2009) em Alagoas (1,68 $\left.\mathrm{Mg} \mathrm{cm}^{-3}\right)$. Cabe ressaltar que, apesar de tratar-se de solos pertencentes à 
mesma classe taxonômica (Argissolos Acinzentados) os mesmos diferem quanto à classe textural, tendo o perfil P4 do presente estudo menores conteúdos de argila e textura franco-arenosa.

Os maiores valores de Ds encontrados no Argissolo Acinzentado (P4) podem estar associados a uma maior concentração de sílica amorfa neste compartimento mais rebaixado da paisagem. Neste caso, por ser um composto solúvel (DREES et al., 1989; OEHLER, 1979) e importante agente cimentante na gênese de horizontes coesos (ARAÚJO FILHO; CARVALHO; SILVA., 2001; CHARTRES et al., 1990; FRANZMEIER; CHARTES; WOOD, 1996; RIBEIRO, 2001), a sílica amorfa produzida pelo intemperismo no topo (perfil P1) e terços superior (perfil P2) e médio (P3) da topossequência seria transportada, via fluxos hídricos laterais, para a porção mais baixa da mesma (Figura 1B). Seu acúmulo gradativo no terço inferior, devido à má drenagem presente, intensificaria o processo de coesão. As maiores Ds encontradas por Lima et al. (2005) e Lima Neto et al. (2009) em Argissolos Acinzentados, também situados em áreas mais rebaixadas, corroboram esta hipótese.

Apesar de terem sido utilizadas amostras de TFSA, os solos com caráter coeso, submetidos a ciclos de umedecimento e secagem, voltaram a manifestar a coesão depois de secos. Os dados referentes à resistência à penetração (RP; Figura 3), evidenciam que os horizontes Bt1 coesos (P2; P3 e P4) apresentaram valores de RP significantemente superiores $(\mathrm{p}<0,05)$ aos do Bt1 não coeso (P1). Isso corrobora com a hipótese de que o caráter coeso se desenvolve sob condições naturais, ou seja, através de processos pedogenéticos, portanto, diferente da compactação que ocasiona aumento na resistência à penetração em função do efeito da pressão, como descrito por Cavalieri et al. (2009) e Freddi et al. (2009).

Embora o valor de RP limitante ao crescimento das raízes e da parte aérea possa variar com as culturas e classes de solo sob diferentes sistemas de manejo (BEUTLER et al., 2004), valores iguais ou superiores a 2,0 MPa são comumente considerados impeditivos para o crescimento das raízes (TAYLOR; ROBERSON; PARKEN, 1996). Dessa forma, os resultados encontrados nos horizontes coesos (Figura 3) devem prejudicar o aprofundamento do sistema radicular e, portanto, funcionar como uma barreira física ao livre crescimento das raízes.

Cabe ressaltar ainda que, como destacam Silveira et al. (2010), a RP é influenciada pela umidade do solo. Dessa forma, avaliando-se a influência da umidade, Giarola et al. (2003) encontraram valores de RP de 4,5 MPa em horizontes coesos com baixa umidade. Deve-se destacar que, embora se tenha utilizado material destorroado e submetido a poucos ciclos de umedecimento e secagem, o valor máximo de RP encontrado neste estudo (7,7 MPa) foi superior àqueles registrados por Giarola et al. (2003) usando amostras indeformadas.
Os valores de RP dos perfis P2 e P4 mostram diferença significativa $(p<0,05)$ entre os tratamentos com e sem a extração de material amorfo (Figura 3). As maiores diferenças entre os tratamentos foram evidenciadas no perfil P4, onde a RP do solo variou de 7,71 a 1,29 MPa, nos tratamentos sem e com extração de material amorfo, respectivamente.

Estas claras diferenças entre os valores de RP nos tratamentos, especialmente aquelas registradas em P2 e P4 (Figura 3), evidenciam a importante ação de compostos amorfos na cimentação temporária e gênese de horizontes coesos.

Figura 3 - Valores médios de resistência a penetração nos horizontes Bt1

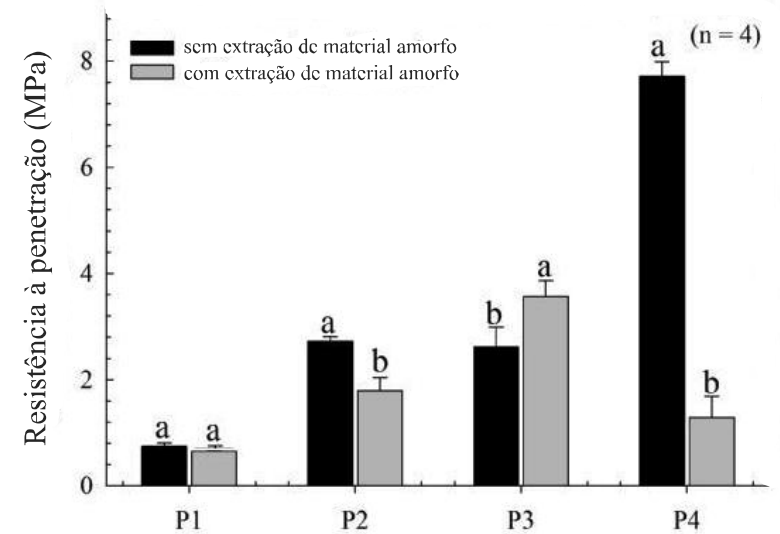

Médias seguidas da mesma letra não diferem entre si pelo teste de Tukey a $5 \%$

De fato, Araújo Filho, Carvalho e Silva (2001) associam a presença de sílica amorfa com o endurecimento dos horizontes coesos, destacando, durante o período seco, seu papel como agente cimentante. Por ser mais solúvel do que a sílica cristalina (OEHLER, 1979) e, no mínimo 10 vezes, mais solúvel que o quartzo (DREES et al.,1989), estes compostos amorfos podem ser mais atuantes na cimentação dos solos. Com base nessas informações, pode-se sugerir que compostos amorfos (pouco cristalinos ou de baixa cristalinidade) são responsáveis, em parte, pela gênese do caráter coeso nos perfis $\mathrm{P} 2$ e P4.

Contrariamente ao observado em P2 e P4, o perfil P3 apresentou aumento nos valores de RP do solo após a extração do material amorfo (Figura 3). No caso específico do $\mathrm{P} 3$, os maiores conteúdos de argila registrados neste perfil em relação aos demais (Tabela 3) podem explicar, em parte, os elevados valores de RP registrados. Sendo assim, esses materiais finos, especialmente argila muito fina (menores que 0,2 $\mu \mathrm{m}$ ), poderiam atuar como pontes entre 
partículas de areia, contribuindo para o aumento da RP do solo seco (MULLINS, 1997) e, inclusive, para o aparecimento do caráter coeso (CORRÊA et al., 2008). A correlação positiva e significativa $(r=0,9310 ; \mathrm{p}<0,01 ; \mathrm{n}=5)$ entre argila e $\mathrm{RP}$, após extração do material amorfo neste perfil, corrobora esta hipótese (Figura 4).

Figura 4 - Correlação entre resistência a penetração do solo e teor argila, em amostras com extração de material amorfo, em solos dos Tabuleiros Costeiros

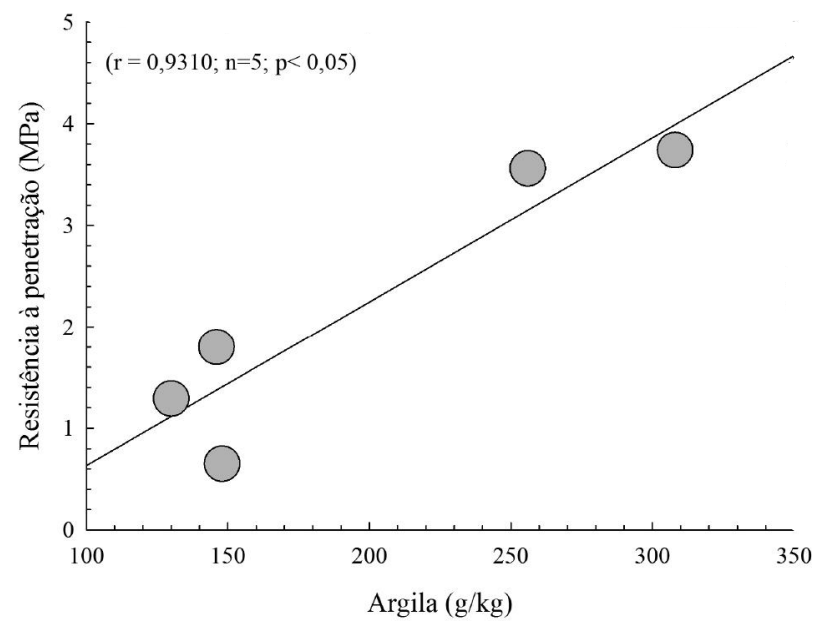

Entretanto, deve-se ressaltar que o comportamento diferenciado no P3 é indicativo de que haja participação de outros fatores, além de compostos amorfos, na gênese de horizontes coesos, conforme sugerido previamente por Cintra, Libardi e Silva (1997).

\section{CONCLUSÕES}

1. Os solos com caráter coeso que passam por processo de destorroamento apresentam alta resistência à penetração após três ciclos de umedecimento e secagem;

2.A maior expressão do caráter coeso no Argissolo Acinzentado, situado na posição mais baixa da paisagem, pode indicar que esta localização favorece a intensificação do caráter coeso, pois o aporte dos fluxos hídricos laterais e a concentração de soluções são favorecidos nessa condição;

3. Após a extração de material amorfo, os horizontes coesos apresentam diminuição da resistência à penetração nos perfis P2 e P4, indicando que estes compostos são atuantes na gênese de horizontes coesos.

\section{REFERÊNCIAS}

AQUINO, D. N. et al. Impacto do manejo da irrigação sobre os recursos solo e água. Revista Ciência Agronômica, v. 39, n. 02, p. 225-232, 2008.

ARAÚJO FILHO, J. C.; CARVALHO, A.; SILVA, F. B. R. Investigações preliminares sobre a pedogênese de horizontes coesos em solos dos tabuleiros costeiros do Nordeste do Brasil. In: WORKSHOP COESÃO EM SOLOS DOS TABULEIROS COSTEIROS, 2001, Aracaju. Anais... Aracaju: Embrapa Tabuleiros Costeiros, 2001. p. 123-142.

BEUTLER, A. N.; CENTURION, J. F.;SILVA, A. P. Intervalo hídrico ótimo e a produção de soja e arroz em dois Latossolos. Irriga, v. 09, n. 02, p. 181-192, 2004.

CAVALIERI, K. M. V. et al. Influência da carga mecânica de máquina sobre propriedades físicas de um cambissolo háplico. Revista Brasileira de Ciência do Solo, v. 33, n. 03, p. 477-485, 2009.

CHARTRES, C. J.; KIRBY, J. M.; AUPACH, M. Poorly ordered silica and aluminosilicates as temporary cementing agents in hard-setting soils. Soil Science Society of America Journal, v. 54 , n. 04 , p. $1060-1067,1990$.

CINTRA, F. L D.; LIBARDI, P. L.; SILVA, A. P. Tabuleiros Costeiros do Nordeste do Brasil: uma análise dos efeitos do regime hídrico e da presença de camada coesas nos solos. Boletim Informativo da Sociedade Brasileira de Ciência do Solo, v. 22, n. 02, p. 77-80, 1997.

CINTRA, F. L. D.; PORTELA, J. C.; NOGUEIRA, L. C. Caracterização física e hídrica em solos dos tabuleiros costeiros no distrito de irrigação Platô de Neópolis. Revista Brasileira de Engenharia Agrícola e Ambiental, v. 08, n. 01, p. 45-50, 2004.

CINTRA, F. L. D. et al. Efeito de volumes de água de irrigação no regime hídrico de solo coeso dos tabuleiros e na produção de coqueiro. Revista Brasileira de Ciência do Solo, v. 33 n. 04, p. 1041-1051, 2009.

CORRÊA, M. M. et al. Caracterização física, química, mineralógica e micromorfológica de horizontes coesos e fragipãs de solos vermelhos e amarelos do ambiente Tabuleiros Costeiros. Revista Brasileira de Ciência do Solo, v. 32, n. 01, p. 297-313, 2008.

COSTA, O. V. et al. Estoque de carbono do solo sob pastagem em área de Tabuleiro Costeiro no sul da Bahia. Revista Brasileira de Ciência do Solo, v. 33, n. 05, p. 1137-1145, 2009.

DREES, L. R. et al. Silica in soils: quartz and disordered silicon polymorps. In: DIXON,J. B.; WEED, S. B (Ed). Minerals in soil environments. 2. ed. Madison: Soil Science Society of America, 1989. p. 913-974.

EMPRESA BRASILEIRA DE PESQUISA AGROPECUÁRIA. Centro Nacional de Pesquisa de Solos. Manual de Métodos de Análise de Solo. 2. ed. Rio de Janeiro: Embrapa Solos, 1997. 212 p.

EMPRESA BRASILEIRA DE PESQUISA AGROPECUÁRIA. Centro Nacional de Pesquisa de Solos. Sistema Brasileiro de Classificação de Solos. Rio de Janeiro: Embrapa, 2006. 306 p.

FRANZMEIER, D. P.; CHARTRES, C. J.; WOOD, J. T. Hardsetting soils in Southeast Australia: Landscape and 
profile processes. Soil Science Society of America Journal, v. 60 , n. 04 , p. $1178-1187,1996$.

FREDDI, O. S. et al. Compactação do solo e produção de cultivares de milho em latossolo vermelho. I - características de planta, solo e índice $S$. Revista Brasileira de Ciência do Solo, v. 33, n. 04, p. 793-803, 2009.

GIAROLA, N. F. B.; SILVA, A. P. Conceitos sobre solos coesos e hardsetting. Scientia Agricola, v. 59, n. 03, p. 613-620, 2002.

GIAROLA, N. F. B. et al. Contribution of natural soil compaction on hardsetting behavior. Geoderma, v. 113, n. 01/02, p. 95-108, 2003.

GIAROLA, N. F. B. et al. Mineralogia e cristalografia da fração argila de horizontes coesos de solos nos Tabuleiros Costeiros. Revista Brasileira de Ciência do Solo, v. 33, n. 01, p. 33-40, 2009.

INSTITUTO DE PESQUISA E ESTRATÉGIA ECONÔMICA DO CEARÁ. Perfil Básico Municipal - Trairi. 2005. 10 p.

LIMA, H. V. et al. Identificação e caracterização de solos coesos no estado do Ceará. Revista Brasileira de Ciência do Solo, v. 28, n. 03, p. 467-476, 2004.

LIMA, H. V. et al. Comportamento físico de um argissolo acinzentado coeso no estado do ceará. Revista Brasileira de Ciência do Solo, v. 29, n. 01, p. 33-40, 2005.

LIMA, H. V. et al. Micromorphology and image analysis of a hardsetting ultisol (Argissolo) in the state of Ceara (Brazil). Geoderma, v. 132, n. 03/04, p. 416-426, 2006.

LIMA NETO, J. A. et al. Caracterização e gênese do caráter coeso em Latossolos Amarelos e Argissolos dos Tabuleiros Costeiros do estado de Alagoas. Revista Brasileira de Ciência do Solo, v. 33, n. 04, p. 1001-1011, 2009.

LIMA NETO, J. A. et al. Atributos químicos, mineralógicos e micromorfológicos de horizontes coesos de Latossolos e Argissolos dos Tabuleiros Costeiros do estado de Alagoas. Revista Brasileira de Ciência do Solo, v. 34, n. 02, p. 473-486, 2010.

MAIA, J. L. T.; RIBEIRO, M. R. Propriedades de um Argissolo Amarelo fragipânico de Alagoas sob cultivo contínuo da cana-de-açúcar. Pesquisa Agropecuária Brasileira, v. 39, n. 01, p. 79-87, 2004.

MELO, V. F. et al. Propriedades químicas e cristalográficas da caulinita e dos óxidos de ferro em sedimentos do Grupo Barreiras no município de Aracruz, estado do Espírito Santo. Revista Brasileira de Ciência do Solo, v. 26, n. 01, p. 53-64, 2002a.
MELO, V. F. et al. Mineralogia das frações areia, silte e argila de sedimentos do Grupo Barreiras no município de Aracruz, estado do Espírito Santo. Revista Brasileira de Ciência do Solo, v. 26, n. 01, p. 29-41, 2002 b.

MOREAU, A. M. S. S. et al. Caracterização de solos de duas topossequências em Tabuleiros Costeiros do sul da Bahia. Revista Brasileira de Ciência do Solo, v. 30, n. 06, p. 1007-1019, 2006 a.

MOREAU, A. M. S. S. et al. Gênese de horizonte coeso, fragipã e duripã em solos do tabuleiro costeiro do sul da Bahia. Revista Brasileira de Ciência do Solo, v. 30, n. 06, p. 1021-1030, 2006b.

MULLINS, C. E. Hardsetting. In: LAL, R. et al. (Ed.). Methods for assessment of soil degradation. Advances in soil science. New York: CRC Press, 1997. p. 109-128.

OEHLER, J. H. Depositon and diagenesis of biogenic sílica. In:TRUDINGER, P. A.; SWAINE, D. J. (Ed). Biogeochemical cycling of mineral-forming elements. Amsterdam: Elsevier, 1979. p. 467-479.

SANTANA, M. B. et al. Atributos físicos do solo e distribuição do sistema radicular de citros como indicadores de horizontes coesos em dois solos de tabuleiros costeiros do estado da Bahia. Revista Brasileira de Ciência do Solo, v. 30, n. 01, p. 01-12, 2006.

SANTOS, et al. Manual de descrição e coleta de solo no campo. 5. ed. Viçosa: SBCS, 2005. 92 p.

SILVEIRA, D. C. et al. Relação umidade versus resistência à penetração para um Argissolo Amarelo distrocoeso no recôncavo da Bahia. Revista Brasileira de Ciência do Solo, v. 34, n. 03 , p. $659-667,2010$.

SOUZA L. D. et al. Avaliação de plantas cítricas, em diferentes profundidades de plantio, em latossolo amarelo dos tabuleiros costeiros. Revista Brasileira de Fruticultura, v. 26, n. 02 , p. $241-244,2004$

TAYLOR, H. M.; ROBERSON, G. M.; PARKER JR, J. J. Soil strength-root penetration realations to médium to coarse-textured soil materials. Soil Science, v. 102, n. 01, p. 18-22, 1996.

VIDAL-TORRADO, P.; LEPSCH, I. F.; CASTRO, S. S. Conceitos e aplicações das relações pedologia-geomorfologia em regiões tropicais úmidas. In: VIDAL-TORRADO, P. et al. (Org.). Tópicos em Ciências do Solo. Viçosa: Sociedade Brasileira de Ciência do Solo, 2005. p. 145-192. v. 04. 